\title{
EFECTO DE LA ESPECIE DE LEGUMINOSA Y LA FUENTE DE CARBOHIDRATOS EN LA CALIDAD FÍSICA Y QUÍMICA DE MEZCLAS PARA ENSILAJE
}

\author{
Michael López-Herrera ${ }^{1}$, Ernesto Briceño-Arguedas ${ }^{2}$
}

\section{RESUMEN}

El objetivo de este experimento fue determinar el efecto de la especie de leguminosa y la fuente de carbohidratos sobre las características físicas y químicas del ensilaje de las mezclas elaboradas a partir de las leguminosas, Arachis pintoi, Vigna unguiculata, Cratylia argentea y Erythrina poeppigiana, con 4 fuentes de carbohidratos (melaza de caña de azúcar, pulpa de cítricos deshidratada, grano de maíz molido y fruto inmaduro de guineo cuadrado). El experimento se desarrolló entre los años 2015 y 2016, este consta de un arreglo factorial $4 \times 4$ de 16 tratamientos. Las mezclas se almacenaron durante 50 días en silos de bolsa con capacidad para $5 \mathrm{~kg}$. Los ensilados analizados presentaron características de olor, color y textura de calidad media a buena. Los valores de $\mathrm{pH}$ fluctuaron entre 4,5 - 5,8 y los valores de nitrógeno amoniacal variaron entre 4,3-14,6\% NH3/NT. Los tratamientos con inclusión de fuentes de almidón y leguminosas arbustivas presentaron los niveles más altos de $\mathrm{pH}$ y nitrógeno amoniacal $(p<0,05)$; por lo tanto, fueron las mezclas ensiladas de menor calidad. La concentración de los ácidos grasos volátiles de los tratamientos varió entre 0,836,46\% MS para el ácido láctico, 2,48 - 6,87\% MS para el ácido acético y 0,13-1,79\% MS para el ácido butírico. También se encontró una alta correlación $(\rho>0,62)$ entre la concentración de los ácidos acético y butírico con el contenido de humedad de las mezclas sin ensilar, por otra parte, el ácido láctico presentó una correlación alta, aunque negativa $(\rho=-0,74)$, todas las correlaciones fueron significativas $p<0,001$. Los tratamientos elaborados a partir de leguminosas arbustivas con azúcares o con pectinas presentaron características físicas y químicas que los califican como ensilados de calidad media a buena. Mientras que los tratamientos elaborados a partir de leguminosas de piso y almidones presentaron características físicas y químicas que los califican como ensilados de regular a mala calidad, esto debido a la poca participación de los almidones en el ensilaje.

Palabras clave: Conservación de Forrajes, Ensilajes de leguminosas, Aditivos, Nitrógeno amoniacal.

\footnotetext{
${ }^{1}$ Universidad de Costa Rica, Escuela de Zootecnia y Centro de Investigaciones en Nutrición Animal. Correo electrónico: michael.lopez@ucr.ac.cr

${ }^{2}$ Finca Agroecológica Vocaré. Correo electrónico: ebriceno@fincasiempreverde.com

Recibido: 14 de marzo, 2017 Aceptado: 12 de junio, 2017
} 


\section{ABSTRACT}

Effect of legume species and the source of carbohydrates on physical and chemical quality of mixtures for silage. The objective of this experiment was to determine the effect of the legume species and the carbohydrate source on the physical and chemical characteristics of silage from mixtures made from the legumes, Arachis pintoi, Vigna unguiculata, Cratylia argentea and Erythrina poeppigiana, with 4 sources of carbohydrates (sugar cane molasses, dehydrated citrus pulp, ground corn kernel and immature saba banana fruit). The experiment was developed between 2015 and 2016, this consists of a $4 \times 4$ factorial arrangement with 16 treatments. The blends were stored for 50 days in bag silos of $5 \mathrm{~kg}$. The silages analyzed had characteristics of smell, color and texture from medium to good quality. The $\mathrm{pH}$ values fluctuated between 4.5 - 5.8 and the ammonia nitrogen values varied between $4.3-14.6 \%$ NH3/TN. Treatments including starch sources and shrub legumes presented the highest levels of $\mathrm{pH}$ and ammonia nitrogen $(\mathrm{p}<0.05)$; therefore, they were the lesser quality ensiled mixtures. The concentration of the volatile fatty acids in the treatments ranged from $0.83-6.46 \%$ MS for lactic acid, $2.48-6.87 \%$ MS for acetic acid and 0.13 $1.79 \%$ MS for butyric acid. A high correlations $(\rho>0.62)$ was found between acetic and butyric acids concentrations and moisture content of non ensiled mixtures. On the other hand, lactic acid showed a high but negative correlation $(\rho=-0.74)$, all correlations were significant $p<0.001$. Treatments made from shrub legumes with sugars or pectins presented physical and chemical characteristics that qualify them as medium to good silage. While the treatments elaborated from floor legumes and starches presented physical and chemical characteristics that qualify them as silage to regulate to poor quality, this due to the little participation of the starches in the silage.

Keywords: Forage conservation, Legumes silage, Additives, Ammonia nitrogen 


\section{INTRODUCCIÓN}

El ensilaje es una técnica de conservación de forraje por vía húmeda, que consiste en almacenar forrajes en estado verde en ausencia de oxígeno, donde ocurren transformaciones químicas y físicas que definen su calidad (Hiriart, 2008). El ensilaje permite mantener la disponibilidad del componente forrajero durante la estación seca o lluviosa, mediante el uso de otros materiales vegetativos como residuos de cosechas, subproductos agroindustriales, frutos, raíces, tubérculos y otros forrajes de uso no tradicional (López-Herrera et al., 2009).

Este proceso se logra por medio de una fermentación láctica espontánea inducida por la microflora epífita en los forrajes, en particular las bacterias productoras de ácido láctico (BPAL) (Davies et al., 1998) bajo condiciones anaeróbicas (Elferink et al., 2005). Esta se ve favorecida por el valor de pH inicial, capacidad buffer inicial del forraje, temperatura, contenido de bacterias, contenido de carbohidratos solubles, el contenido de materia seca y el volumen de aire por volumen de material (Moore y Peterson, 1995)

Para la determinación de la calidad del proceso de ensilaje se pueden utilizar análisis químicos y/o físicos, que involucran el uso de tecnología o el uso de la percepción sensorial. Algunos de los análisis son: pH, Nitrógeno amoniacal, ácidos grasos volátiles y pruebas sensoriales (Hiriart, 2008), tal como: color, olor y buena textura (Betancourt et al., 2005).

En los ensilajes de leguminosas se debe considerar que estas plantas poseen mayor capacidad amortiguadora que las gramíneas, por su alto contenido de proteína (Moore y Peterson, 1995), lo que obliga a reforzar el contenido de carbohidratos disponibles para las BPAL; esto permite optimizar el proceso de ensilaje, por una rápida reducción del pH (Giger-Reverdin et al., 2002). Esto coincide con lo publicado por Playne y McDonald (1966) quienes indican que la capacidad amortiguadora de los forrajes es influenciada por las proteínas de la planta entre $10-12 \%)$, la fibra $(10-12 \%)$ y los aniones orgánicos $(70-80 \%)$.

Otras investigaciones han determinado que es posible obtener ensilados de calidad a partir de leguminosas, siempre y cuando haya una adecuada concentración de carbohidratos en la mezcla forrajera (McDonald, 1981). Castillo et al., (2009) determinaron valores de $\mathrm{pH}$ entre 3,1 - 3,6 y concentraciones de nitrógeno amoniacal $2,5-3,9 \% \mathrm{NH} 3 / \mathrm{NT}$ en ensilados elaborados con Vigna radiata y Maíz. Por su parte, 
Tobía et al., (2008) quienes analizaron ensilados de soya, obtuvieron valores entre 4,0 - 5,9 para el potencial de hidrógeno, 6,0 - 21,1\% NH3/NT y 4,4-6,6\% MS de ácido láctico, donde los mejores valores de cada variable coinciden con el mayor aporte de melaza de caña de azúcar.

El objetivo de este experimento es determinar el efecto de la especie de leguminosa y la fuente de carbohidratos en las características físicas y químicas de los ensilados obtenidos a partir de mezclas forrajeras.

\section{MATERIALES Y MÉTODOS}

Los forrajes para el experimento fueron obtenidos de la finca Agroecológica Vocaré ubicada en el cantón de Upala a 120 - 180 msnm, con una precipitación promedio de $2500 \mathrm{~mm}$ anuales y una temperatura promedio de $25^{\circ} \mathrm{C}$. No obstante, la parte experimental se llevó a cabo en el Campus Rodrigo Facio de la Universidad de Costa Rica, ubicado en San Pedro de Montes de Oca donde se localizan los laboratorios de Centro de Investigaciones en Nutrición Animal (CINA) ahí se realizaron los análisis de características organolépticas y de parámetros químicos.

Los forrajes de leguminosas se cosecharon de acuerdo al tipo de forraje (herbáceo o arbustivo), de manera que no sean forrajes muy maduros con alto contenido de fibra y lignina. Las edades de corte que se utilizaron fueron: Vigna unguiculata (40 días), Arachis pintoi (40 días), Cratylia argentea (75 días) y Erythrina poeppigiana (75 días).

Los niveles de inclusión de las fuentes de carbohidratos fueron: melaza $(6,3 \% \mathrm{p} / \mathrm{p})$, pulpa de cítricos deshidratada (PCD) $(8,4 \% \mathrm{p} / \mathrm{p})$, maíz molido $(6,4 \% \mathrm{p} / \mathrm{p})$ y fruto inmaduro de guineo cuadrado $(6,7 \% \mathrm{p} / \mathrm{p})$ de manera que provean $5 \%$ del total de carbohidratos no fibrosos de la mezcla. El 5\% restante para alcanzar el $10 \%$ de carbohidratos no fibrosos, fue aportado por las leguminosas. El fruto inmaduro de guineo cuadrado se encontraba en estado inmaduro y completamente engrosado al momento de la cosecha.

El experimento consta de un diseño factorial completamente aleatorizado $(4 \times 4)$, con 4 fuentes de carbohidratos (melaza de caña de azúcar, pulpa de cítricos deshidratada, maíz molido y fruto de guineo cuadrado) y 4 especies leguminosas (Vigna unguiculata, Arachis pintoi, Cratylia argéntea y Erythrina poeppigiana), para un total de 16 
tratamientos. Todos los tratamientos se uniformizaron para que contaran con $10 \%$ de carbohidratos no fibrosos, para asegurar una adecuada fermentación de acuerdo a lo planteado por Vargas (1979) e Hiriart (2008). Además, se les agregó inóculo bacterial artesanal (elaborado por fermentación anaeróbica en la finca a partir de suero de leche, leche y melaza - Lactobacillus $1,0 \times 10^{9}$ ) (1L/tonelada) con base en el peso en fresco; para todos los tratamientos. . Cada tratamiento fue repetido 4 veces para un total de 64 microsilos, además cada bolsa se consideró como una unidad experimental.

El proceso de ensilaje se realizó mediante la técnica de microsilos, para este fin se utilizó bolsas de polietileno para empaque al vacío con capacidad para $5 \mathrm{~kg}$ y con un grosor de 0,0063 mm, cada bolsa se llenó con $4 \mathrm{~kg}$ de mezcla para ensilar. El material una vez depositado y compactado a mano, se extrajo el aire a fondo mediante una aspiradora. Posterior a la eliminación del oxigeno, las bolsas se sellaron con cinta plástica adhesiva y se colocaron en condiciones de laboratorio $\left(25^{\circ} \mathrm{C}, 75 \%\right.$ humedad relativa, aproximadamente) por 50 días, donde estuvieran protegidas del ataque de aves, roedores o labores rutinarias que podrían perjudicar el proceso de ensilaje. Adicionalmente se tomó una muestra en fresco que fue transportada para ser analizada en el CINA.

La muestra sin ensilar fue ingresada al CINA para determinar el contenido de materia seca mediante la metodología descrita en el manual de la AOAC (1998). Después de 50 días de fermentación se realizó la apertura de los silos, de cada bolsa se tomó $1 \mathrm{~kg}$ de mezcla ensilada para determinar las características organolépticas del material, utilizando los indicadores planteados por Betancourt et al., (2005), para color, olor y textura, además se utilizó una escala de graduación donde: el color se calificó de la siguiente manera: $0=$ negro, $1=$ pardo, $2=$ verde pardo, $3=$ verde oscuro y $4=$ verde olivo. El olor se calificó de acuerdo a la escala: 0=butírico, 1=acético fuerte, 2=acético leve, $3=$ =áctico. Finalmente, la textura se calificó con la escala: $0=$ =mucilago, 1=suave, 2=medio, $3=$ firme $y$ consistente.

El material restante se utilizó para determinar la concentración de nitrógeno amoniacal mediante la metodología empleada por Tobía (2004) y el pH fue medido utilizando un potenciómetro de hidrógeno. Para la determinación de los ácidos grasos volátiles, se utilizó la técnica de Cromatografía Líquida de Alta Resolución (HPLC), descrita por Canale et al., (1984) mediante el uso de una columna de Hi-Plex H marca Agilent. 
El análisis de la información se realizó con un Modelo ANOVA de INFOSTAT y por medio de contrastes ortogonales (Di Rienzo et al., 2015) considerando como efectos principales: la fuente de carbohidratos (C), la especie de leguminosa (L) y la interacción de todas las fuentes principales $\left(L^{*} C\right)$. Para el análisis de la evaluación organoléptica se utilizó la prueba de Kruskal Wallis para análisis de la varianza no paramétrica con un nivel de confianza de $95 \%$. También se realizó un análisis de correlación de Pearson entre todas las variables de evaluación organolépticas, de fermentación y el contenido de humedad del ensilado. Finalmente, para la comparación entre medias de los tratamientos se utilizó la prueba de Tukey con un nivel de confianza del $95 \%$.

\section{RESULTADOS Y DISCUSIÓN}

Características organolépticas de los materiales ensilados

\section{$\underline{\text { Color }}$}

El color de los materiales ensilados fue afectado $(p<0,0001)$ por la interacción entre la especie de leguminosa y la fuente de carbohidratos agregado (Cuadro 1). Todos los tratamientos presentaron coloraciones mayores al grado 3 en la escala de graduación utilizada, es decir colores verdes. Sólo los tratamientos donde se combinó Arachis, con fruto de guineo, pulpa de cítricos deshidratada o maíz; la escala de color presentó una calificación menor a 3, es decir colores pardos o negros.

De acuerdo a Betancourt et al., (2005) e Hiriart, (2008), la coloración de un ensilado puede indicar el tipo de proceso que se desarrolló en el silo, aunque siempre se espera un cambio de color en los materiales conservados. Se espera que ensilados donde ocurren adecuados procesos de ensilaje, posean coloraciones desde verde amarillento hasta verde pardo, debido a que los ácidos orgánicos actúan sobre la clorofila, la cual pierde su magnesio, por lo que tiende a colores pardos o dorados. También se debe considerar que en las cáscaras de los plátanos y bananos se producen colores pardos por la actividad de la polifenol oxidasa, y que puede estar activa durante el ensilaje ya que se mantiene activa a pH 4-7,5 (Ngalani et al., 1993).

Al contrario, materiales con coloraciones oscuras o negro se relacionan a procesos de ensilaje donde ocurre fuerte oxidación de los forrajes, debido a menor compactación 
del material y a una elevación de la temperatura en el silo, por lo que ocurre una carbonización de los compuestos orgánicos del forraje. De esta manera, estos colores oscuros se relacionan a ensilados de mala calidad, ya que los carbohidratos más disponibles han sido oxidados en el proceso de ensilaje.

Cuadro 1. Clasificación de los indicadores organolépticos de las mezclas de leguminosas con diferentes tipos de carbohidratos, posterior a 50 días de fermentación. San José, Costa Rica. 2016.

\begin{tabular}{|c|c|c|c|c|}
\hline Leguminosa & $\mathrm{CHO}^{*}$ & Color $^{\S}$ & Olor & Textura \\
\hline \multirow{4}{*}{ Vigna } & Melaza & $3,25^{b}$ & $1,75^{\mathrm{abc}}$ & $3,00^{c}$ \\
\hline & $\mathrm{PCD}^{* *}$ & $3,00^{\mathrm{b}}$ & $1,25^{\mathrm{abc}}$ & $1,00^{\mathrm{a}}$ \\
\hline & Maíz & $3,00^{\mathrm{b}}$ & $1,00^{\mathrm{ab}}$ & $2,00^{\mathrm{b}}$ \\
\hline & Guineo & $3,50^{\mathrm{b}}$ & $0,50^{\mathrm{a}}$ & $1,00^{\mathrm{a}}$ \\
\hline \multirow{4}{*}{ Arachis } & Melaza & $3,00^{b}$ & $1,25^{\mathrm{abc}}$ & $2,00^{b}$ \\
\hline & PCD & $1,00^{\mathrm{a}}$ & $2,00^{\mathrm{abc}}$ & $2,00^{\mathrm{b}}$ \\
\hline & Maíz & $2,75^{\mathrm{b}}$ & $1,50^{\mathrm{abc}}$ & $2,00^{\mathrm{b}}$ \\
\hline & Guineo & $0,00^{\mathrm{a}}$ & $1,00^{\mathrm{ab}}$ & $1,00^{\mathrm{a}}$ \\
\hline \multirow{4}{*}{ Cratylia } & Melaza & $4,00^{b}$ & $3,00^{\mathrm{C}}$ & $3,00^{\mathrm{C}}$ \\
\hline & PCD & $4,00^{\mathrm{b}}$ & $3,00^{\mathrm{c}}$ & $3,00^{\mathrm{c}}$ \\
\hline & Maíz & $3,00^{\mathrm{b}}$ & $2,50^{\mathrm{bc}}$ & $3,00^{c}$ \\
\hline & Guineo & $3,33^{b}$ & $2,67^{\mathrm{bc}}$ & $3,00^{\mathrm{C}}$ \\
\hline \multirow{4}{*}{ Erythrina } & Melaza & $4,00^{b}$ & $1,00^{\mathrm{ab}}$ & $3,00^{c}$ \\
\hline & PCD & $4,00^{\mathrm{b}}$ & $3,00^{\mathrm{c}}$ & $3,00^{c}$ \\
\hline & Maíz & $4,00^{b}$ & $2,75^{\mathrm{bc}}$ & $3,00^{c}$ \\
\hline & Guineo & $4,00^{b}$ & $2,50^{\mathrm{bc}}$ & $3,00^{c}$ \\
\hline \multicolumn{2}{|c|}{ Leguminosa (L) } & $<0,0001$ & $<0,0001$ & $<0,0001$ \\
\hline \multicolumn{2}{|c|}{ Fuente de carbohidratos (C) } & 0,0028 & - & 0,0061 \\
\hline \multicolumn{2}{|c|}{$\mathrm{LxC}$} & $<0,0001$ & - & - \\
\hline
\end{tabular}

Los colores obtenidos en esta investigación son similares a los obtenidos por Van Man y Wiktorsson (2002) con ensilados de Gliricidia sepium, con diferentes niveles de inclusión de melaza, además fueron similares a los encontrados por Elizondo-Salazar y Campos-Granados (2014), con ensilados de cáscaras de piña con heno y urea, también fueron similares a los resultados obtenidos por López-Herrera et al., (2009) 
quienes trabajaron con ensilados utilizando pulpa de cítricos deshidratada como material absorbente de humedad.

\section{$\underline{\text { Olor }}$}

Esta variable fue afectada $(p<0,01)$ por la especie de leguminosa forrajera en el silo (Cuadro 1). La fuente de carbohidratos no tuvo efecto sobre el olor del silo, de acuerdo a la escala utilizada, sin embargo, los tratamientos con inclusión de pulpa de cítricos deshidratada presentaron un leve olor a naranja, esto coincide con lo encontrado en el trabajo de López-Herrera et al., (2009) quienes trabajaron con ensilados utilizando pulpa de cítricos deshidratada como material absorbente de humedad.

El olor es una característica organoléptica que permite conocer el desarrollo del proceso de ensilaje, ya que depende de la concentración y tipo de ácidos orgánicos que se hayan producido durante el ensilaje (Adesogan, 2006). Se espera que durante el proceso de ensilaje se produzcan todo tipo de ácidos orgánicos, aunque es deseable que sea mayor la concentración de ácido láctico o al menos que el ácido butírico esté ausente (Betancourt et al., 2005). Los olores dulces son propios de los procesos donde hubo formación de ácido láctico, sin embargo, también pueden ser obtenidos cuando ocurre fermentación alcohólica producto del metabolismo de levaduras (Driehuis y van Wikselaar, 2000), esto se debe a que el alcohol se une a los ácidos orgánicos y forma ésteres de olor agradable (Hiriart, 2008).

Por otra parte, olores desagradables y a putrefacción son propios de materiales de mala calidad, donde se ha generado ácido butírico (Betancourt et al., 2005). Los silos donde se obtienen valores de $\mathrm{pH}$ mayor a 4,4 generalmente muestran mayores concentraciones de ácido butírico, debido a mayor actividad de bacterias clostridiales, las cuales reducen la calidad del forraje conservado ya que aumentan las pérdidas de materia seca y de proteína en el ensilado (Adesogan, 2006). Además, aumenta la concentración de nitrógeno amoniacal (Mc Donald, 1981).

Los tratamientos donde se utilizaron especies arbustivas o arbóreas presentaron olores más dulces o con poco olor acético, mientras que los tratamientos donde se utilizaron leguminosas herbáceas tendieron a presentar olor acético, donde los tratamientos elaborados a partir de Vigna fueron los de mayor olor acético. De acuerdo a Kung y Shaver (2001) olores muy fuertes a ácido acético se relacionan a concentraciones entre $5-6 \%$ MS de ácido acético en el ensilado, lo que puede 
provocar rechazo del material, lo que reduce el consumo voluntario del animal. Solamente el tratamiento Vigna-Guineo presentó olor butírico o a material descompuesto.

$\underline{\text { Textura }}$

Esta variable fue afectada $(p<0,05)$ por los efectos individuales de la especie de leguminosa forrajera y la fuente de carbohidratos utilizada en la mezcla ensilada (Cuadro 1). Se detectó alta correlación $(\rho=0,70)$ entre el olor y la textura de los materiales, no así con el color de los ensilados, de esta manera un ensilado que presenta buen olor, presentará muy buena textura, mientras que materiales con mal olor, asociado a producción de ácido butírico; se correlaciona con ensilados con texturas pegajosas y mucilaginosas. Al igual que con el olor, los tratamientos donde se utilizaron especies arbustivas o arbóreas presentaron mejor textura que los tratamientos donde se utilizaron leguminosas herbáceas, ya que estas últimas presentan en promedio textura suave a media.

Los tratamientos donde se utilizó melaza como fuente de carbohidratos, fueron los que presentaron mejor textura, mientras que en los que se utilizó fruto de guineo cuadrado se obtuvo la textura menos aceptable. A pesar de esto, todos los tratamientos presentaron texturas entre media a buena, lo que los clasifica como ensilajes de excelente a buena calidad (Betancourt et al., 2005).

\section{Características químicas del ensilaje}

\section{Potencial de hidrógeno $(\mathrm{pH})$ :}

El grado de acidificación del ensilaje fue afectado por el tipo de carbohidrato agregado a la mezcla ensilada (Cuadro 2). De esta manera las mezclas que contienen carbohidratos más disponibles como la melaza, presentaron niveles de $\mathrm{pH}$ menores $(p<0,05)$ con respecto a los tratamientos donde se utilizó fuentes de carbohidratos en forma de almidones, además, los tratamientos con inclusión de fruto de guineo cuadrado, presentaron niveles de $\mathrm{pH}$ mayores $(p<0,05)$, esto puede ser debido a la disponibilidad de los carbohidratos presentes en el almidón al momento del inicio del proceso de ensilaje. De acuerdo a Pelissari et al., (2012) el almidón es el componente principal de los guineos inmaduros, además Ravi y Mustaffa (2013) señalan que los frutos de musáceas pueden contener hasta $85 \%$ de almidón y de este alrededor del 
$57 \%$ puede ser resistente a la degradación, por lo que se puede asumir una baja participación de estos carbohidratos en el ensilaje.

Los valores obtenidos en los tratamientos con melaza, son aceptables cuando se trabaja con materiales con bajo contenido de materia seca $(<20 \% \mathrm{MS}$ ) (McDonald, 1981), mientras el resto de los tratamientos presentó valores de $\mathrm{pH}$ que permiten la proliferación de bacterias clostridiales, mohos y levaduras que reducen la calidad organoléptica y nutricional del material conservado (Moore y Peterson, 1995). Por su parte Kung y Shaver (2001) indican que al ensilar forrajes de leguminosas con contenidos de materia seca menores a $30 \%$, se obtienen valores de $\mathrm{pH} 4,6-4,8$, que permiten procesos de fermentación clostridial, lo que reafirma la idea anterior.

Cuadro 2. Valores de $\mathrm{pH}$ y nitrógeno amoniacal (NH3/NT) de las mezclas de leguminosas con diferentes fuentes de carbohidratos, a 50 días de fermentación y materia seca (MS) antes del ensilaje. San José, Costa Rica. 2016.

\begin{tabular}{|c|c|c|c|c|}
\hline Leguminosa & $\mathrm{CHO}^{*}$ & $\mathrm{pH}$ & NH3/NT (\%) & MS (\%) \\
\hline \multirow{4}{*}{ Vigna } & Melaza & $4,5^{\mathrm{a}}$ & $4,3^{\mathrm{a}}$ & $13,52^{\mathrm{a}}$ \\
\hline & $P C D^{\star *}$ & $5,4^{\mathrm{c}}$ & $11,7^{\mathrm{c}}$ & $17,26^{\mathrm{b}}$ \\
\hline & Maíz & $4,9^{\mathrm{b}}$ & $6,4^{\mathrm{b}}$ & $13,12^{\mathrm{a}}$ \\
\hline & Guineo & $5,4^{\mathrm{c}}$ & $14,6^{\mathrm{d}}$ & $10,99^{a}$ \\
\hline \multirow{4}{*}{ Arachis } & Melaza & $4,7^{\mathrm{a}}$ & $4,9^{\mathrm{a}}$ & $13,28^{\mathrm{a}}$ \\
\hline & PCD & $4,9^{\mathrm{b}}$ & $8,5^{\mathrm{b}}$ & $17,85^{\mathrm{b}}$ \\
\hline & Maíz & $5,1^{\mathrm{b}}$ & $7,8^{\mathrm{b}}$ & $14,99^{\mathrm{a}}$ \\
\hline & Guineo & $5,1^{\mathrm{D}}$ & $11,9^{\mathrm{c}}$ & $11,66^{\mathrm{a}}$ \\
\hline \multirow{4}{*}{ Cratylia } & Melaza & $4,8^{\mathrm{a}}$ & $7,8^{\mathrm{b}}$ & $20,74^{\mathrm{b}}$ \\
\hline & PCD & $5,0^{\mathrm{b}}$ & $9,1^{\mathrm{b}}$ & $21,64^{\mathrm{b}}$ \\
\hline & Maíz & $5,8^{\mathrm{c}}$ & $12,3^{\mathrm{c}}$ & $19,51^{\mathrm{b}}$ \\
\hline & Guineo & $5,8^{\mathrm{c}}$ & $10,7^{\mathrm{c}}$ & $19,05^{\mathrm{b}}$ \\
\hline \multirow{4}{*}{ Erythrina } & Melaza & $4,5^{\mathrm{a}}$ & $4,7^{\mathrm{a}}$ & $20,01^{\mathrm{D}}$ \\
\hline & PCD & $4,7^{\mathrm{a}}$ & $6,6^{\mathrm{b}}$ & $22,24^{\mathrm{b}}$ \\
\hline & Maíz & $5,1^{\mathrm{b}}$ & $10,0^{\mathrm{c}}$ & $18,29^{b}$ \\
\hline & Guineo & $5,2^{\mathrm{b}}$ & $10,7^{\mathrm{c}}$ & $17,34^{\mathrm{b}}$ \\
\hline \multicolumn{2}{|c|}{ Leguminosa (L) } & $<0,0001$ & 0,0050 & $<0,0001$ \\
\hline \multicolumn{2}{|c|}{ Tipo de carbohidrato (C) } & $<0,0001$ & $<0,0001$ & $<0,0001$ \\
\hline \multicolumn{2}{|c|}{ LxC } & 0,0014 & $<0,0001$ & - \\
\hline
\end{tabular}

* Fuente de carbohidratos, ** Pulpa de cítricos deshidratada.

${ }^{a, b}$ Letras diferentes en la misma columna son estadísticamente diferentes $(p<0,05)$ 
El aumento en el valor de $\mathrm{pH}$ final en los tratamientos ensilados con fuentes como el maíz, la pulpa de cítricos y el fruto de guineo cuadrado, puede ser debido a los carbohidratos agregados a la mezcla, es decir que, a pesar de uniformizar todos los tratamientos con único nivel de CNF, se debe considerar la fuente de carbohidratos dominante en los aditivos utilizados, ya que fuentes con menos contenidos de azúcares y mayor concentración de almidones no permiten una adecuada conservación de los forrajes.

Esto concuerda con lo publicado por Rojas (1985) quien señala que, la acidificación durante el proceso de ensilaje, inactiva las amilasas bacterianas, por tal motivo, los almidones no son aprovechados por las bacterias y por lo tanto no participan en el proceso de ensilaje. Por su parte, Jones (1988) afirma que fue posible recuperar 90 $100 \%$ del almidón de cebada y avena, adicionado a ensilados de pasto ryegrass (Lolium sp.). Además, Mülhbach (2001) señala que cuando se utilizó maíz como fuente de carbohidratos $(5-10 \% \mathrm{p} / \mathrm{p})$ en mezclas para ensilaje de pasto estrella africana (Cynodon nlemfuensis) y Desmodium uncinatum; fue posible mantener adecuada fermentación en el silo hasta el $30 \%$ de leguminosa en la mezcla, además indica que al utilizar niveles mayores a $30 \%$ de leguminosa, se debe complementar la mezcla con melazas para obtener una fermentación adecuada.

De esta manera, los valores obtenidos en esta investigación son similares a los publicados por Tobía et al., $(2008)(4,01-5,81)$ con ensilajes de soya sin adición de Lactobacillus, pero mayores a los valores reportados por Mustafa y Seguin (2003) $(3,85-4,3)$ con ensilajes de Guisante (Pisum sativum), Haba (Vicia faba) y Soya (Glicine max), a los 45 días de fermentación. También fueron mayores a los valores publicados en el trabajo de Krizsan y Randby (2007) en ensilados de pastos de clima templado, salvo los tratamientos donde se utilizó melaza como fuente de carbohidratos, ya que estos presentaron valores similares. Estas diferencias se deben al bajo contenido de azúcares solubles en la pulpa de cítricos, y a la baja participación de los almidones como fuente de energía en el proceso de ensilaje.

\section{Nitrógeno amoniacal (NH3/NT):}

Al igual que con el $\mathrm{pH}$, la fuente de carbohidratos generó diferencias $(p<0,05)$ en la concentración de nitrógeno amoniacal de los tratamientos ensilados. También la especie de leguminosa generó diferencias $(p<0,05)$ en la concentración de $\mathrm{NH} 3 / \mathrm{NT}$ 
(Cuadro 2). Los tratamientos donde se utilizó melaza, presentaron menores concentraciones de nitrógeno amoniacal debido a mayor acidificación durante el ensilaje. Al no acidificar el medio dentro del silo, aumenta la proliferación de bacterias, como las enterobacterias, cuyas proteasas degradan las proteínas mediante el proceso de desaminación. En esta investigación se encontró correlación positiva $(\rho=0,70)$, entre la variable de $\mathrm{pH}$ y la concentración de nitrógeno amoniacal, situación que refuerza la necesidad de disminuir el $\mathrm{pH}$, para evitar las pérdidas de calidad del material forrajero; lo anterior coincide con los hallazgos realizados en el trabajo de Fransen y Strubi (1998).

En lo que respecta a la especie de leguminosa, las diferencias tienen su origen en el contenido de humedad de la mezcla al inicio del ensilaje, de acuerdo a Hiriart (2008) materiales con alto contenido de humedad (> $80 \%)$, poseen mayores concentraciones de $\mathrm{NH} 3 / \mathrm{NT}$. De igual manera en esta investigación fue posible correlacionar $(\rho=0,75)$ de manera significativa $(p<0,001)$ el contenido de humedad y la concentración de NH3/NT, esto coincide con lo reportados por Kung y Shaver (2001) quienes señalan que ensilajes de forrajes con alto contenido de humedad ( $<30 \% \mathrm{MS})$, como los obtenidos en esta investigación (Cuadro 2), presentan mayores concentraciones de nitrógeno amoniacal debido a potenciales fermentaciones clostridiales; debido a esto son necesarias medidas que permitan aumentar el contenido de materia seca en las mezclas donde se utilicen estos forrajes.

Fransen y Strubi (1998) obtuvieron concentraciones menores de nitrógeno amoniacal utilizando diferentes materiales absorbentes de humedad, además López-Herrera et al., (2009) (2,36 - 3,27\% NH3/NT) y López-Herrera et al., (2015) $(1,70-6,40 \%$ $\mathrm{NH} 3 / \mathrm{NT}$ ) indican que, cuando se utilizan aditivos con baja concentración de humedad, como la pulpa de cítricos y el heno, se reducen las pérdidas por nitrógeno amoniacal en el silo. A pesar de esto, se debe considerar la fuente de carbohidratos utilizada, la cantidad de carbohidrato agregado, la capacidad amortiguadora de las leguminosas y el contenido de humedad de la mezcla al inicio del proceso de ensilaje, motivo por el cual los valores obtenidos fueron mayores a los reportados en los trabajos citados anteriormente. 


\section{Ácidos orgánicos de los ensilados}

Todos los ácidos orgánicos fueron afectados de manera significativa $(p<0,05)$ por la interacción entre la especie de leguminosa y la fuente de carbohidratos, a excepción del ácido propiónico que sólo presenta diferencias significativas $(p<0,05)$ provocadas por la especie de leguminosa (Cuadro 3).

Cuadro 3. Concentración de ácidos orgánicos, en las mezclas de leguminosas con diferentes tipos de carbohidratos, posteriores a 50 días de fermentación. San José, Costa Rica. 2016.

\begin{tabular}{|c|c|c|c|c|c|}
\hline Leguminosa & $\mathrm{CHO}^{*}$ & $\begin{array}{l}\text { Láctico } \\
\text { (\%MS) }\end{array}$ & $\begin{array}{l}\text { Acético } \\
\text { (\%MS) }\end{array}$ & $\begin{array}{c}\text { Butírico } \\
\text { (\%MS) }\end{array}$ & $\begin{array}{c}\text { Propiónico } \\
\text { (\%MS) }\end{array}$ \\
\hline \multirow{4}{*}{ Vigna } & Melaza & $4,06^{b}$ & $4,27^{b}$ & $0,51^{\mathrm{a}}$ & $0,62^{\mathrm{b}}$ \\
\hline & $\mathrm{PCD}^{* *}$ & $0,82^{\mathrm{a}}$ & $6,26^{c}$ & $1,16^{b}$ & $0,54^{\mathrm{b}}$ \\
\hline & Maíz & $1,29^{\mathrm{a}}$ & $4,44^{b}$ & $0,80^{\mathrm{a}}$ & $0,56^{\mathrm{b}}$ \\
\hline & Guineo & $0,83^{a}$ & $6,40^{\mathrm{c}}$ & $1,79^{\mathrm{b}}$ & $0,55^{\mathrm{b}}$ \\
\hline \multirow{4}{*}{ Arachis } & Melaza & $1,37^{\mathrm{a}}$ & $5,09^{b}$ & $0,67^{\mathrm{a}}$ & $0,50^{b}$ \\
\hline & PCD & $1,43^{\mathrm{a}}$ & $4,90^{\mathrm{b}}$ & $1,29^{\mathrm{b}}$ & $0,33^{\mathrm{a}}$ \\
\hline & Maíz & $2,02^{a}$ & $5,59^{b}$ & $1,16^{\mathrm{b}}$ & $0,51^{\mathrm{D}}$ \\
\hline & Guineo & $0,91^{a}$ & $6,87^{c}$ & $1,54^{\mathrm{b}}$ & $0,47^{\mathrm{b}}$ \\
\hline \multirow{4}{*}{ Cratylia } & Melaza & $6,46^{\mathrm{C}}$ & $2,48^{a}$ & $0,13^{a}$ & $0,31^{\mathrm{a}}$ \\
\hline & PCD & $6,16^{\mathrm{c}}$ & $2,84^{a}$ & $0,16^{a}$ & $0,26^{a}$ \\
\hline & Maíz & $4,35^{\mathrm{b}}$ & $4,08^{\mathrm{b}}$ & $0,32^{\mathrm{a}}$ & $0,29^{a}$ \\
\hline & Guineo & $3,25^{\mathrm{b}}$ & $4,98^{\mathrm{b}}$ & $0,37^{\mathrm{a}}$ & $0,34^{\mathrm{a}}$ \\
\hline \multirow{4}{*}{ Erythrina } & Melaza & $5,41^{\mathrm{C}}$ & $4,53^{b}$ & $0,37^{\mathrm{a}}$ & $0,40^{\mathrm{a}}$ \\
\hline & PCD & $5,03^{c}$ & $4,01^{\mathrm{b}}$ & $0,15^{\mathrm{a}}$ & $0,29^{\mathrm{a}}$ \\
\hline & Maíz & $3,83^{b}$ & $4,16^{\mathrm{b}}$ & $0,19^{a}$ & $0,28^{a}$ \\
\hline & Guineo & $2,38^{a}$ & $4,91^{\mathrm{D}}$ & $0,31^{a}$ & $0,46^{\mathrm{b}}$ \\
\hline \multicolumn{2}{|c|}{ Leguminosa (L) } & $<0,0001$ & $<0,0001$ & $<0,0001$ & $<0,0001$ \\
\hline \multicolumn{2}{|c|}{ Tipo de carbohidrato (C) } & $<0,0001$ & $<0,0001$ & 0,0049 & - \\
\hline \multicolumn{2}{|c|}{ LxC } & 0,0001 & $<0,0001$ & $<0,0001$ & - \\
\hline
\end{tabular}

* Fuente de carbohidratos, ${ }^{* *}$ Pulpa de cítricos deshidratada.

${ }_{a, b}$ Letras distintas en la misma columna son diferentes $(p<0,05)$.

Las diferencias en cuanto a la especie de leguminosa provienen de la cantidad de humedad presente en el material forrajero, de hecho, en esta investigación se 
determinaron correlaciones medias y altas entre el contenido de humedad del forraje y la concentración de los ácidos orgánicos en el ensilado, así, el ácido acético, el ácido butírico y el ácido propiónico presentaron correlaciones de Pearson positivas $\rho=0,70$, $\rho=0,62$ y $\rho=0,65$, respectivamente, mientras que el ácido láctico presentó correlación de Pearson $\rho=-0,74$, esto concuerda con los hallazgos de otras investigaciones donde se recomienda que los forrajes altos en humedad deben recibir un proceso de pérdida de agua antes del proceso de ensilaje (Muck y Shinners, 2001; Han et al., 2006).

También se determinaron correlaciones de Pearson negativas entre ácidos, entonces, conforme aumenta la concentración del ácido acético, disminuye la concentración del ácido láctico $(\rho=-0,73)$ y cuando aumenta la cantidad de ácido butírico en el silo, se reduce la cantidad de ácido láctico $(\rho=-0,70)$. Estos dos procesos coinciden con lo publicado en McDonald (1981) e Hiriart (2008), quienes indican que, durante el proceso de ensilaje, la cantidad y el tipo de ácidos orgánicos producidos dependen de las poblaciones de bacterias presentes en el silo y que esto a su vez está determinado por la capacidad de acidificación de los ácidos producidos.

De acuerdo al análisis de contrastes el promedio de los tratamientos elaborados con leguminosas arbustivas, presentaron mayor producción de ácido láctico, con respecto al promedio de los tratamientos elaborados con leguminosas herbáceas $(p<0,001)$ (Figura 1), esto es debido a que las leguminosas arbustivas poseen mayor contenido de materia seca, lo que favorece el crecimiento y actividad de las BPAL, situación que propicia la acidificación dentro del silo, que asegura un forraje de buena calidad (Kung y Shaver, 2001). A su vez, se determinó que el promedio de los tratamientos elaborados con Cratylia exhibió mayor producción de ácido láctico en comparación al promedio de los ensilados de Erythrina, esto puede ser debido a un efecto de carbohidratos solubles en el forraje, ya que no hay diferencias en el contenido de materia seca entre los tratamientos elaborados con estas leguminosas.

En cuanto al efecto de la fuente de carbohidratos, se comprobó que en promedio los tratamientos donde se utilizó melaza, presentaron las mayores producciones de ácido láctico, en comparación con el promedio de los tratamientos elaborados con otras fuentes de carbohidratos $(p<0,001)$, también se determinó que en promedio los tratamientos con pulpa de cítricos deshidratada, fueron los que registraron la segunda mejor producción de ácido láctico, con respecto al promedio de los tratamientos en los que se utilizaron fuentes almidonosas $(p<0,001)$, esto sugiere que hubo poca participación de los almidones como sustrato para las BPAL, de manera que el 
promedio de producción de ácido láctico para el maíz y el fruto de guieno cuadrado es el más bajo.

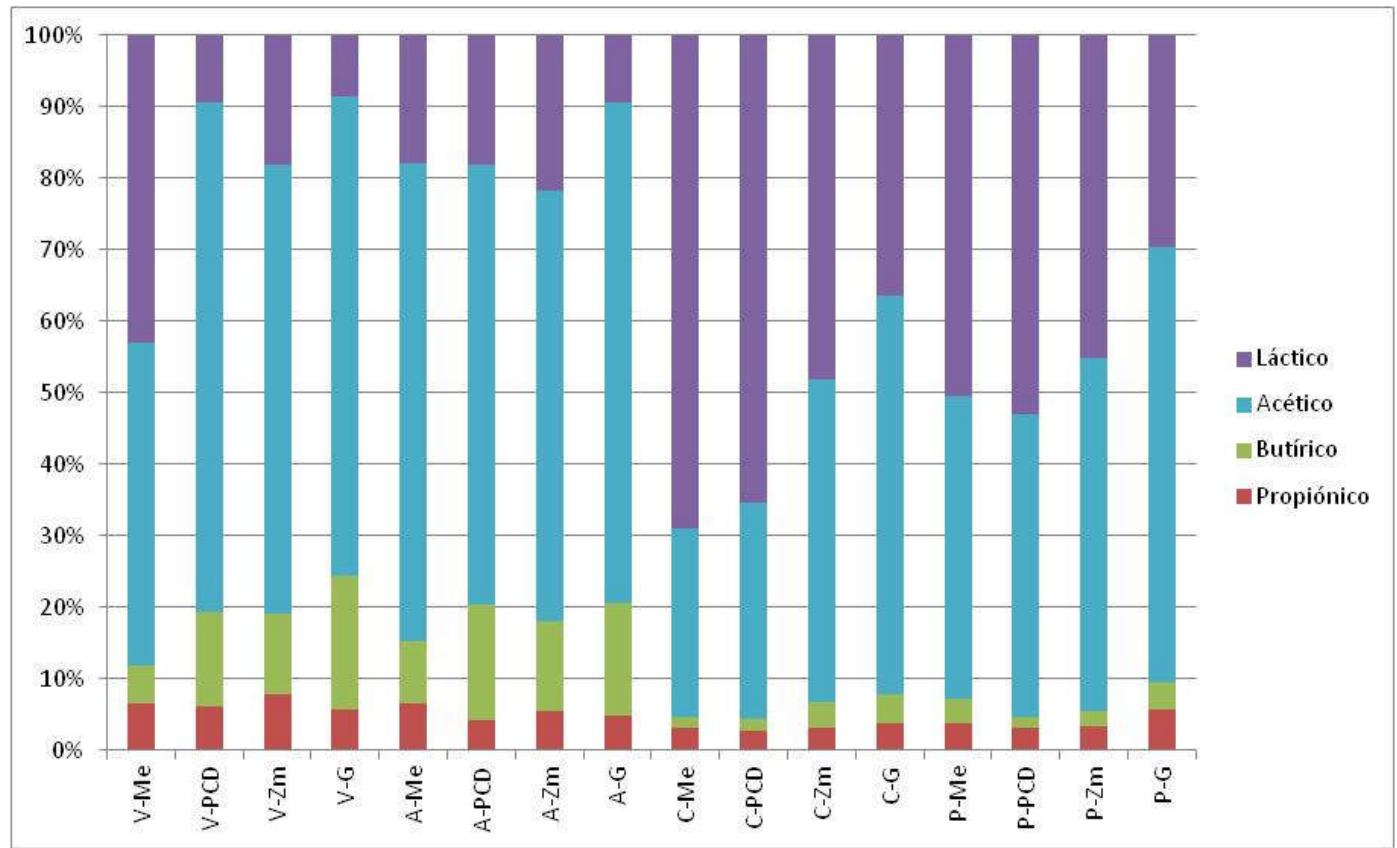

Figura 1. Proporciones de cada ácido orgánico en las mezclas de leguminosas con diferentes tipos de carbohidratos, posteriores a 50 días de fermentación. San José, Costa Rica. 2016.

Finalmente, hubo diferencias de un punto porcentual entre el promedio de los tratamientos donde se utilizó maíz y en los que se utilizó fruto de guineo cuadrado $(p<0,001)$, en este caso la producción de ácido láctico fue mayor a favor del maíz. Estas diferencias son debidas a la disponibilidad y velocidad con que las bacterias pueden convertir los carbohidratos en ácidos orgánicos y de esta manera, acidificar el medio para asegurar la conservación de la calidad del forraje (Jones, 1988; Yang et al., 2006).

En promedio por especie de leguminosa y por fuente de carbohidrato los valores de ácido láctico obtenidos en esta investigación fueron menores a los obtenidos por Fransen y Strubi (1998) $(5,52-6,12 \% \mathrm{MS})$, aunque similares a los reportados por Kung Jr et al., (2003) (3,61 - 4,45 \%MS) con ensilados de alfalfa. Sin embargo, fueron menores a los valores encontrados por Van Man y Wiktorsson (2002) (9,9-9,9\%MS). 
Estas diferencias se deben al contenido de materia seca de los forrajes y el contenido de azúcares solubles en la mezcla, los cuales pueden aumentar o deprimir la producción del ácido láctico en el silo, tal y como se comentó con anterioridad.

La producción de ácido acético y ácido butírico aumenta cuando no se dan las condiciones favorables para la producción de ácido láctico (McDonald, 1981). Así, el promedio de producción de los ácidos acético y butírico en los tratamientos elaborados con leguminosas herbáceas es mayor que el promedio de los tratamientos elaborados con leguminosas arbustivas $(p<0,01)$. No obstante, no de determinó diferencias entre los promedios de los tratamientos elaborados con leguminosas herbáceas. Además, la concentración de estos ácidos aumenta cuando se utilizan fuentes de carbohidratos almidonosas (Figura 1).

Todos los tratamientos a excepción de Cratylia-melaza y Cratylia PCD presentan contenidos de ácido acético y butírico mayores a los reportados en el trabajo de Betancourt et al., (2005), como ideales para ensilados de leguminosas de buena calidad. Esto puede ser debido al contenido de humedad en los forrajes, junto al efecto de la fuente de carbohidratos, lo que predispone mayores poblaciones de bacterias heterofermentativas que producen más cantidad de ácido acético, lo que reduce la calidad del proceso fermentativo (Elferink et al., 2005) y podría deprimir el consumo del ensilado cuando su concentración es mayor al 6\% (Kung y Shaver, 2001); como ocurre con los tratamientos elaborados a partir de Vigna y Arachis, con guineo cuadrado como fuente de carbohidratos.

En cuanto al contenido de ácido butírico, los tratamientos elaborados a partir de leguminosas herbáceas, fueron los que presentaron mayor concentración de este ácido y sobre todo, los tratamientos donde se utilizaron almidones como aditivos; en estos tratamientos el coeficiente de correlación de Pearson entre el contenido de ácido butírico y la cantidad de nitrógeno amoniacal presentó valores positivos $\rho=0,69$ $(p<0,001)$, lo que sugiere malos procesos de conservación en el silo; y por este motivo no utilizar estas mezclas en animales ya que se puede afectar su salud. De acuerdo a Cook et al., (2006) el consumo de ensilados con alta concentración de ácido butírico puede predisponer la aparición de cetosis tipo tres en cualquier momento de la lactancia temprana en vacas lecheras, por un aumento en la cantidad de BHB (betahidroxibutirato) en sangre. 


\section{CONSIDERACIONES FINALES}

Los ensilados de leguminosas con diferentes fuentes de carbohidratos presentaron características organolépticas de calidad media a buena, estas diferencias fueron determinadas por el grado de compactación del material, el contenido de materia seca y la capacidad amortiguadora de cada especie de leguminosa, además de la fuente de carbohidratos utilizada en la mezcla forrajera.

Los valores de potencial de hidrógeno y nitrógeno amoniacal presentaron niveles aceptables para ensilados tropicales, en especial cuando se utilizó melaza como fuente de carbohidratos, esto debido a su alto contenido de azúcares solubles (46\% MS). Sin embargo, cuando se utilizó maíz y fruto de guineo cuadrado se detectaron los valores más elevados para estas variables, lo que presume una pérdida de calidad en el forraje conservado. También se encontró diferencias entre las fuentes maíz y guineo cuadrado debido a que el maíz en grano posee aproximadamente $1,7 \%$ MS de azúcares, que pueden actuar durante el ensilaje, caso contrario del fruto de guineo cuadrado que es sòlo almidón cuando está en estado inmaduro, tal y como se utilizó en este experimento.

La concentración de ácidos orgánicos en el ensilado está relacionada con los valores de potencial de hidrógeno y la concentración de nitrógeno amoniacal en los ensilados, por lo que son afectados por el contenido de materia seca, la capacidad amortiguadora del forraje y la concentración de carbohidratos solubles en la mezcla forrajera antes del ensilaje. De esta manera, cuando se utilizó melaza en la mezcla para ensilaje se propició la producción de ácido láctico, en detrimento de la concentración de los ácidos acético y butírico. Mientras que al utilizar fruto de guineo cuadrado inmaduro se obtuvo menor producción de ácido láctico y se incrementó la síntesis de los ácidos acético y butírico; el primero puede afectar el consumo voluntario del ensilado y el segundo provoca pérdidas de calidad en el material por descomposición. 


\section{LITERATURA CITADA}

Adesogan, A.T. 2006. Factors affecting corn silage quality in hot and humid climates. In: Proceedings of the 17th Florida Ruminant Nutrition Symposium. February $1-2$, 2006. University of Florida. United States. $108-127$

AOAC (Association of Official Analytical Chemist). 1998. Official Methods of Analysis of AOAC International. 16th ed, 4th rev. Gaithersburg, MD, USA.

Betancourt, J.C. 2004. Caracterización nutricional y productiva de material fresco y ensilado de maní forrajero (Arachis pintoi) cultivado en asocio con maíz (Zea mays), a tres densidades de siembra. Tesis de maestría, Universidad de Costa Rica. Costa Rica. 110 p.

Betancourt, M., I. González, y M. Martínez De Acurero. 2005. Evaluación de la calidad de los ensilajes. Revista Digital Centro Nacional de Investigaciones Agropecuarias de Venezuela. No8 mayo-agosto. Maracay, Aragua, Venezuela. 1-5 pp. Disponible en:

http://sian.inia.gob.ve/repositorio/revistas_tec/ceniaphoy/articulos/n8/arti/betancourt _m/betancourt_m.htm, consultado el viernes 12 de enero de 2016 a las 9:15 am.

Canale, A., M.E. Valente, y A. Ciotti. 1984. Determination of volatile carboxylic acids (C1 - C5i) and lactic acid in aqueous acid extracts of silage by high performance liquid chromatography. Journal of the Science of Food and Agriculture 35(11): 1178 $-1182$

Castillo M., A. Rojas-Bourrillon, y R. WingChing-Jones. 2009. Valor nutricional del ensilaje de maíz cultivado en asocio con vigna (Vigna radiata). Agronomía Costarricense 33(1): $133-146$.

Cook N., G. Oetzel, y K. Nordlund. 2006. Modern techniques for monitoring highproducing dairy cows: 2. Practical applications. In Practice-London-British Veterinary Association 28(10): $598-603$ 
Cubero, J.F., A. Rojas-Bourrillón, y R. Wingching 2010. Uso del inóculo microbial elaborado en finca en ensilaje de maíz (Zea mays). Valor nutricional y fermentativo. Agron. Costarric. 34(2): 237-250.

Davies D.R., R.J. Merry, A.P. Williams, E.L. Bakewell, D.K. Leemans, y J.K.S. Tweed. 1998. Proteolysis during ensilage of forages varying in soluble sugar content. Journal of Dairy Science 81(2): $444-453$.

Di Rienzo, J.A., F. Casanoves, M.G. Balzarini, L. Gonzalez, M. Tablada, y Y.C. Robledo. 2015. Infostat versión 2015. Grupo infostat, FCA, Universidad Nacional de Córdoba, Argentina. http://www.infostat.com.ar

Driehuis F., y P.G. Van Wikselaar. 2000. The occurrence and prevention of ethanol fermentation in high dry matter grass silage. Journal of the Science of Food and Agriculture 80(6): $711-718$.

Elferink O., F. Driehuis, J.C. Gottschal, y S.F. Spoelstra. 2005. Los procesos de fermentación del ensilaje y su manipulación. Institute for Animal Science and Health. Holanda. p. $1-14$

Elizondo-Salazar J.A., y C.M. Campos-Granados. 2014. Características nutricionales de la cáscara de piña ensilada con cantidades crecientes de urea y heno. Nutrición Animal Tropical 8(2): 51- 71.

Ewen A. 2011. Organic acids in silage: Aplication note. Agilent Technologies. Estados Unidos. p. 3.

Fransen S.C., y F.J. Strubi. 1998. Relationships among absorbents on the reduction of grass silage effluent and silage quality. Journal of Dairy Science 81(10): 2633 2644.

Giger-Riverdin S., C. Duvaux-Ponter, D. Sauvant, O. Martin, I. Nunes Do Prado, y R. Müller. 2002. Intrinsic buffering capacity of feedstuffs. Animal Feed Science and Technology. 96: 83-102

Han K.J., M. Collins, E.S. Vanzant, y C.T Dougherty. 2006. Characteristics of baled silage made from first and second harvests of wilted and severely wilted forages. Grass and Forage Science 61(1): $22-31$. 
Hiriart M. 2008. Ensilados. Procesamiento y Calidad. Editorial Trillas. México. p. 110.

Jones, D.I.H. 1988. The effect of cereal incorporation on the fermentation of spring-and autumn-cut silages in laboratory silos. Grass and Forage Science 43: 167-172.

Jones, R., y D.I.H. Jones. 1996. The effect of in-silo effluent absorbents on effluent production and silage quality. Journal of Agricultural Engineering Research 64(3): 173-186.

Krizsan S.J., y A.T. Randby. 2007. The effect of fermentation quality on the voluntary intake of grass silage by growing cattle fed silage as the sole feed. Journal of Animal Science 85(4): $984-996$.

Kung L., y N.K. Ranjit. 2001. The effect of Lactobacillus buchneri and other additives on the fermentation and aerobic stability of barley silage. Journal of Dairy Science 84(5): 1149 - 1155.

Kung L., y R. Shaver. 2001. Interpretation and use of silage fermentation analysis reports. Focus on forage: $3(13): 1-5$.

Kung L., C.C. Taylor, M.P. Lynch, y J.M. Neylon. 2003. The effect of treating alfalfa with Lactobacillus buchneri 40788 on silage fermentation, aerobic stability, and nutritive value for lactating dairy cows. Journal of Dairy Science 86(1): $336-343$.

López-Herrera, M., R. WingChing y A. Rojas-Bourrillon. 2009. Características fermentativas y nutricionales del ensilaje de rastrojo de piña (Ananas comosus). Agronomía Costarricense 33(1): 1 - 15.

López-Herrera, M., R. WingChing, A. Rojas-Bourrillon y S. Rodríguez. 2015. Valoración nutricional de ensilajes de corona de piña con adición de heno y urea. Nutrición Animal Tropical 9(2): 65-90.

McDonald P. 1981. The biochemistry of silage. John Wiley, New York.

McDonald P., y A.R. Henderson. 1962. Buffering capacities of herbage samples as factor of silage. Journal of Science Food and Agriculture 13:395-400. 
Moore K.J., y M.A. Peterson. 1995. Post-harvestphysiology and preservation of forages. Crop Science Society of America Inc. Special publication N. ${ }^{\circ} 22$. Wisconsin, USA. p. 91-107.

Muck R.E., y K.J. Shinners. 2001. Conserved forage (silage and hay): progress and priorities. In: International Grassland Congress, XIX. Brazilian Society of Animal Husbandry São Pedro, Brazil. p. 753 - 762.

Mühlbach P.R. 2001. Uso de aditivos para mejorar el ensilaje de los forrajes tropicales. In: Memorias de la conferencia electrónica de la FAO sobre el ensilaje en los trópicos. Estudio FAO producción y protección vegetal 161: 157 - 171.

Mustafa A.F., y P. Seguin. 2003. Characteristics and in situ degradability of whole crop faba bean, pea, and soybean silages. Canadian Journal of Animal Science 83(4): $793-799$.

Ngalani J.A., A. Signoret, y J. Crouzet. 1993. Partial purification and properties of plantain polyphenol oxidase. Food Chemistry 48(4): $341-347$.

Pelissari F.M., M.M. Andrade-Mahecha, P.J.D.A Sobral, y F.C. Menegalli. 2012. Isolation and characterization of the flour and starch of plantain bananas (Musa paradisiaca). Starch/Stärke 64(5): $382-391$.

Playne M. J., y P. McDonald. 1966. The buffering constituents of herbage and of silage. Journal of the Science of Food and Agriculture 17: $264-268$

Ravi, I., y M.M. Mustaffa. 2013. Starch and amylose variability in banana cultivars. Indian Journal of Plant Physiology 18(1): 83 - 87.

Rojas-Bourrillon A. 1985. Effect of rolled corn silage on digesstion of nutrients and feedlot performance of growing steers. Tesis de Maestría. lowa Sate University. United States. p. 93.

Tobia C. 2004. Introducción del ensilaje de soya en un sistema de producción intensiva de leche en el trópico húmedo de Costa Rica. Tesis de Doctorado. Universidad de Costa Rica, San José, Costa Rica. p. 120.

Tobia C., y E. Villalobos. 2004. Producción y valor nutricional del forraje de soya en condiciones tropicales adversas. Revista Agronomía Costarricense 28(1): 17 - 25. 
Tobía C., E. Villalobos, A. Rojas, H. Soto, y K.J. Moore. 2008. Nutritional value of soybean (Glycine max L. Merr.) silage fermented with molasses and inoculated with Lactobacillus brevis 3. Livestock Research for Rural Development 20(7): 1 - 9.

Van Man N., y H. Wiktorsson. 2002. Effect of molasses on nutritional quality of cassava and gliricidia tops silage. Asian Australasian Journal of Animal Sciences 15(9): 1294 $-1299$

Vargas R. 1979. Determinación de la composición química y el valor nutritivo del pasto elefante (Pennisetum purpureum) ensilado en microsilos con tres niveles de melaza. Tesis de Licenciatura. Universidad de Costa Rica. Costa Rica. p. 37.

Yang H.Y., X.F. Wang, J.B Liu, L.J. Gao, M. Ishii, Y. Igarashi, y Z.J. Cui. 2006. Effects of water-soluble carbohydrate content on silage fermentation of wheat straw. Journal of bioscience and bioengineering 101(3): $232-237$. 